\title{
Cystatin C and Acute Kidney Injury in Acute Heart Failure; Impact on Hospital Course
}

\author{
${ }^{1}$ Ahmed Elbarbary, ${ }^{2}$ Lobna Refaat, ${ }^{3}$ Mohamed Awadein, ${ }^{4}$ Ahmed Tamara \\ ${ }^{1}$ Cardiology Department, ${ }^{2}$ Clinical Pathology, ${ }^{3}$ Internal Medicine, Faculty of Medicine,Misr University for Science \\ and Technology, MUST University, ${ }^{4}$ Cardiology Department, Faculty of Medicine, Ain Shams University \\ *Corresponding author: Ahmed Elbarbary, Mobile: (+20)01222333615
}

\begin{abstract}
Introduction: Acute heart failure (AHF) is a life-threatening disease with a high mortality rate. Cardio-renal syndrome (CRS) has received much attention because of its relation to the poor prognosis of hospitalized patients. In both acute and chronic cardiac disease, kidney impairment is a significant predictor of outcome. Finding a more sensitive renal damage marker is a top priority due to the disadvantage of the existing marker creatinine. Several new acute kidney injury (AKI) biomarkers are being studied. Cystatin Cis a kidney function biomarker that has also been investigated for its use in acute kidney injury early detection.

Aim: was to assess the outcome of using cystatin $\mathrm{C}$ as a new AKI biomarker in patients diagnosed with AHF and its effect on hospital stay and in-hospital mortality.

Methods: Cystatin C levels were measured on admission and 48 hours later in 200 hospitalized AHF patients. The amount of increase in cystatin $\mathrm{C}$ after 48 hours was measured, as well as the impact of a cystatin $\mathrm{C}$ increase on the hospital course.

Results: The mean population age was 66.4 years old, while $49 \%$ of the population were females. AKI was detected in $16 \%$ of patients with $>0.3 \mathrm{mg} / \mathrm{L}$ rise in cystatin $\mathrm{C}$ within two days of hospital admission, and this led to 3 days $(\mathrm{P}=$ $0.01)$ significant more extended hospital stay while in-hospital mortality was more but could not reach statistical significance $(\mathrm{P}=0.239)$.

Conclusion: In patients with acute heart failure, elevation in Cystatin $\mathrm{C}$ within 48 hours of hospital admission is a good detector of early acute kidney injury and has a detrimental impact on their hospital course.

Keywords: Acute heart failure, Cystatin C, Acute renal injury.
\end{abstract}

\section{INTRODUCTION}

Acute heart failure (AHF) is a life-threatening disease with accelerated worsening of heart failure, leading to a high death rate. ${ }^{(1,2)}$ Renal impairment is one of the most common and most crucial predictors of chronic heart disease outcomes and AHF hospitalization. ${ }^{(3,4)}$ The acute cardio-renal syndrome (CRS) known as (Type 1) is characterized by worsening of kidney functionfollowing acute heart failure patients $(5,6)$. Renal function declines often following AHF hospitalization, and it has been linked to poor prognosis and higher mortality rates ${ }^{(7,8)}$.

Serum creatinine is used to evaluate kidney function. However, using serum creatinine as a measure of renal impairment has several drawbacks. Age has a significant impact on serum creatinine, and it is also affected by other factors like sex and muscle mass ${ }^{(9,10)}$. Furthermore, serum creatinine is not a perfect biomarker of renal damage. It has been shown that renal injury can happen without an increase in the GFR as measured by serum creatinine. The baseline renal function is a primary determining factor for kidney injury staging by detecting the change in serum creatinine, so when baseline renal function is normal, serum creatinine levels begin to rise at a late stage of renal injury, but when the patient has already a renal failure, the creatinine level changes are exaggerated because creatinine level change is magnified because it has a comparatively significant amount change (For example, a $50 \%$ increase in serum creatinine from 0.5 $\mathrm{mg} / \mathrm{dL}$ to $2.0 \mathrm{mg} / \mathrm{dL}$ result in $1.0 \mathrm{mg} / \mathrm{dL}$ and $3.0 \mathrm{mg} / \mathrm{dL}$, respectively) $)^{(11)}$.

Deteriorating kidney function might be described by a rise of more than $25 \%$, or the absolute level increased by $0.3 \mathrm{mg} / \mathrm{dL}$ from baseline in the initial stages of acute kidney injury (24-48 hours). Due to the slow kinetics of serum creatinine, a significant reduction in eGFR can result in only minor differences in serum creatinine levels ${ }^{(12)}$.

Cystatin C, a protein consisting of a $13.3 \mathrm{kDa}$, belongs to the cysteine protease inhibitors group. It is produced by all nucleated cells and filtered through the glomerulus, and neither secreted nor absorbed into the renal tubules bloodstream. However, tubular epithelial cells partially metabolize it ${ }^{(1,4)}$.

Cystatin $\mathrm{C}$ may identify the variations in glomerular filtration rate (GFR) more easily and quickly than creatinine, which suggested that it may be used as a valuable biomarker of acute renal damage in hospitalized patients in the intensive care unit. Unlike serum creatinine, cystatin $\mathrm{C}$ is unaffected by the age, sex, race, or body mass of the patient. It can be a more sensitive renal failure indicator than serum creatinine since it is only affected by thyroid dysfunction and steroid consumption $^{(12,13)}$. 


\section{AIM OF WORK}

This study aimed to evaluate using cystatin $\mathrm{C}$ as a new AKI biomarker in patients diagnosed with AHF and its impact on hospital stay and in-hospital mortality.

\section{METHODS}

Two hundred patients who needed hospitalization for AHF were recruited in our study.

\section{Ethical approval:}

The study was approved by the MUST university ethics committee,the study begin from January 2017 to June 2019 and informed written consent was obtained from all individual participants included in the study.

On admission, clinical records, including demographics, comorbidities, and prescriptions were carefully recorded. The AHF diagnosis should be confirmed during the hospital stay to fulfill the inclusion criteria.

We handled Blood samples at presentation and 48 hours after hospitalization. Cystatin $\mathrm{C}$ was analyzed using a DakoCytomation immune-turbidimetric assay, with an intra-assay coefficient of variation (CV) of $2 \%$ and inter-assay CV of $4.1 \%$ at $0.7 \mathrm{mg} \backslash$ Liter.The upper limit of cystatin $\mathrm{C}$ references of young and healthy individuals is $1.2 \mathrm{mg} / \mathrm{L}$, and $1.4 \mathrm{mg} / \mathrm{L}$ for people aged more than fifty years.

We used the Modification of Diet in Renal Disease equation (MDRD) to estimate GFR (eGFR). This is an equation initially consisting of six variables, namely age, sex, race, serum creatinine, urea, and albumin that have been simplified to four variables only, including age, sex, race, and serum creatinine ${ }^{(10)}$.

Regarding our study, we reported both values of cystatin $\mathrm{C}$ and other labs on the patient's admission and 48 hours later. In-hospital mortalities were recorded, and the duration of stay for patients who were discharged was registered.

\section{Statistical analysis}

SPSS software (version 15.0.1) was used for statistical analysis. First, we assessed the prevalence, diagnostic performance, and their impact on the study outcomes. Then, using the ROC curve, we analyzed cystatin C efficacy as a specific biomarker for AKIdiagnosis.AKI is defined when cystatin $\mathrm{C}$ is increased by $0.3 \mathrm{mg} / \mathrm{L}$ between the two measured
samples.For other interpretations, we assessed the characteristics variations between patients with and without AKI.

A multivariable logistic regression analysis was conducted to assess the independent consequence of AKI on mortality and for possible confounders such as age, gender, previous medical history, previous medication, and cardiac morbidities on admission.

We used numbers and percentages (\%) to present our data. Furthermore, in normally distributed data, mean and standard deviation (SD) were used. Whenever the variables were not normally distributed, the median with interquartile range (IQR) was used. In addition, we used the chi-square test to analyze Dichotomous variables and the student's t-test or Mann-Whitney U-test for continuous variables. Pearson's correlation was done between cystatin $\mathrm{C}$ and creatinine or eGFR. ROC analysis was used to assess the overall predictivity and detect the best cut-off value, sensitivity, and specificity. P-values $\leq 0.05$ were assumed significant.

\section{RESULTS}

We classified all patients into two groups according to increase in cystatin C level $\geq 0.3 \mathrm{mg} / \mathrm{Lfrom}$ early admission to 48 hours of hospitalization into:

- Group A: patients with AKI (increased cystatin $\mathrm{C} \geq 0.3 \mathrm{mg} / \mathrm{L}$ ).

- Group B: patient without AKI (increased cystatin $\mathrm{C}<0.3 \mathrm{mg} / \mathrm{L}$ ).

Table (1) showed no significant difference between both groups as regards age, sex, medical history and clinical presentation except acute coronary syndrome on admission, which was significantly higher in group A (40\%) compared to group B (22\%) with a significant difference $\mathrm{P}$-value $=0.026$.

\section{The effect of acute renal injury on hospital outcomes:}

Group A patients with AKI (detected by increased cystatin $\mathrm{C} \geq 0.3 \mathrm{mg} / \mathrm{L}$ within two days of admission) had a significantly longer hospital stay period (11 days) compared to group 2 (8 days) (P-value $=0.014)$. Furthermore, group A in-hospital mortality was higher $(6.3 \%)$ than group B $(2.4 \%)$ but this increase was not significant $(\mathrm{P}=0.239)$ (table 1). 
Table (1): Clinical and demographic data of the study population

\begin{tabular}{|l|c|c|c|c|}
\hline Characteristics & All, $\boldsymbol{n = 2 0 0}$ & $\begin{array}{c}\text { Group1 } \\
\text { AKI, } \boldsymbol{n = 3 2}\end{array}$ & $\begin{array}{c}\text { Group2 } \\
\text { No AKI, } \boldsymbol{n}=\mathbf{1 6 8}\end{array}$ & $\boldsymbol{P}$-value \\
\hline Age (years) & $66.4(10.3)$ & $69.0(7.5)$ & $65.9(9.3)$ & 0.077 \\
\hline Male gender & $102(51.0 \%)$ & $14(43.8 \%)$ & $88(52.4 \%)$ & 0.374 \\
\hline Medical history & & & & \\
\hline Previous heart failure & $118(59.0 \%)$ & $16(50.0 \%)$ & $102(60.7 \%)$ & 0.261 \\
\hline Coronary artery disease & $118(59.0 \%)$ & $22(68.8 \%)$ & $96(57.1 \%)$ & 0.219 \\
\hline Myocardial infarction & $54(27.0 \%)$ & $10(31.3 \%)$ & $44(26.2 \%)$ & 0.553 \\
\hline Hypertension & $118(59.0 \%)$ & $21(65.6 \%)$ & $97(57.7 \%)$ & 0.406 \\
\hline Diabetes & $70(35.0 \%)$ & $12(37.5 \%)$ & $58(34.5 \%)$ & 0.745 \\
\hline Chronic atrial fibrillation & $58(29.0 \%)$ & $9(28.1 \%)$ & $49(29.2 \%)$ & 0.900 \\
\hline Cerebrovascular disease & $34(17.0 \%)$ & $7(21.9 \%)$ & $27(16.1 \%)$ & 0.425 \\
\hline Clinical presentation & & & & \\
\hline ACS on admission & $50(25.0 \%)$ & $13(40.6 \%)$ & $37(22.0 \%)$ & $0.026^{*}$ \\
\hline LVEF, \% & $32(16.0 \%)$ & $5(15.6 \%)$ & $27(16.1 \%)$ & 0.944 \\
\hline NYHA class IIIIV & $144(72.0 \%)$ & $27(84.4 \%)$ & $117(69.6 \%)$ & 0.088 \\
\hline Outcomes & & & & \\
\hline Hospital stay days & $7(5-13)$ & $11(6-16)$ & $8(5-11)$ & $0.014^{*}$ \\
\hline Mortality in hospital & $6(3.0 \%)$ & $2(6.3 \%)$ & $4(2.4 \%)$ & 0.239 \\
\hline
\end{tabular}

ACS, acute coronary syndrome; LVEF, left ventricular ejection fraction, NYHA, New York Heart Association.

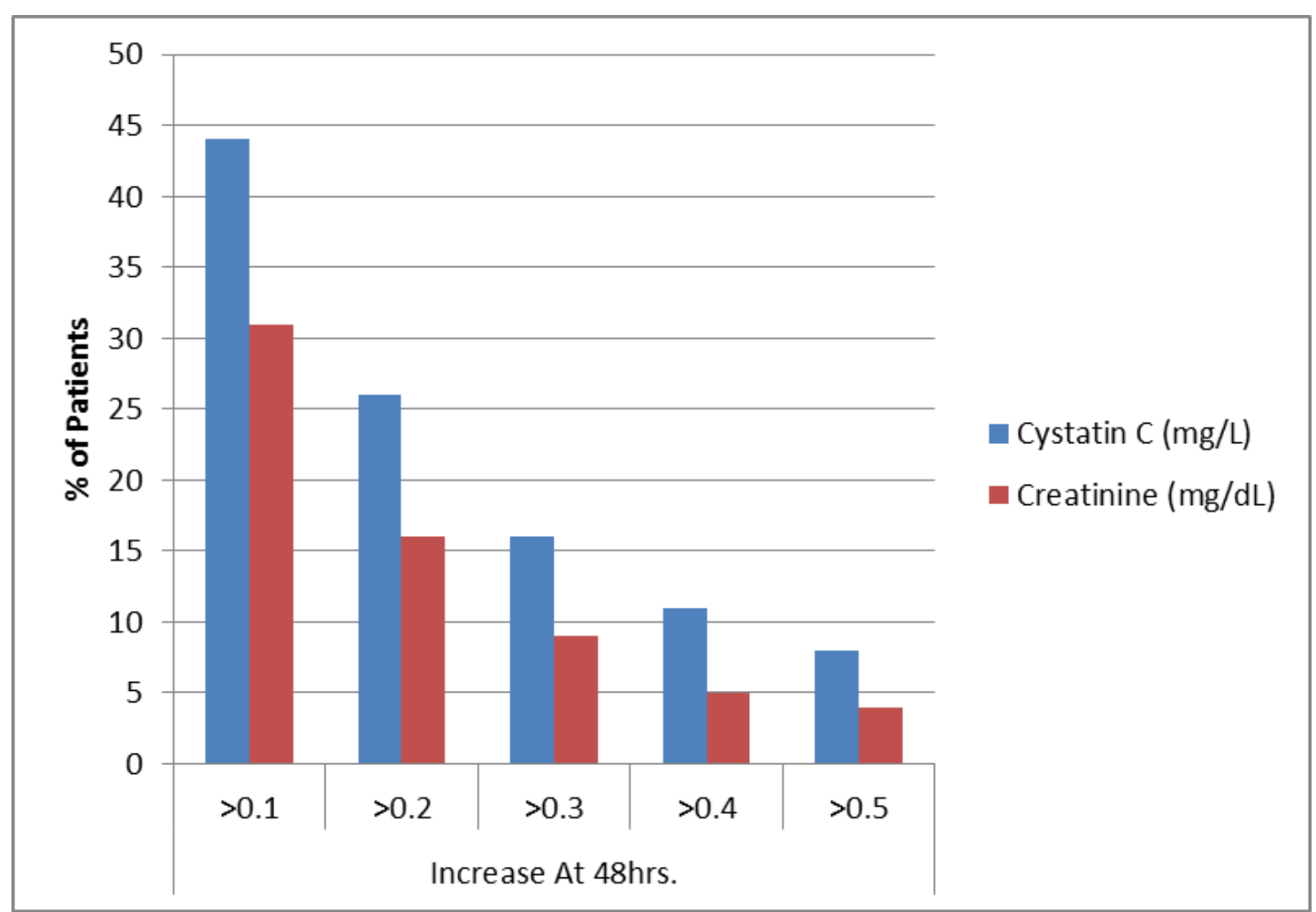

Fig. (1): Incidence of increase incystatin $C$ and creatinine, 48 hours post-hospitalization in patients with acute heart failure. 


\section{Incidence of acute kidney injury:}

As shown in figure (1), within 48 hours, 88 patients (44\% of the studied cohort) showed a cystatin $\mathrm{C}$ rise of more than $0.1 \mathrm{mg} \backslash \mathrm{L}$, whereas only $31 \%$ of the same population showed elevated serum creatinine more than $0.1 \mathrm{mg} \backslash \mathrm{L} . A$ rise more than $0.3 \mathrm{mg} / \mathrm{L}$ elevation in cystatin C levels was notedin $32(16 \%)$ of the patients. A similar rise in serum creatinine was observed in only $9 \%$ of patients.

A reduction in eGFR above $15 \mathrm{~mL} / \mathrm{min}(15 \%)$ or a creatinine increase by $0.2 \mathrm{mg} / \mathrm{dL}$ was associated with deteriorating renal function (16\%).There was a strong correlation between cystatin $\mathrm{C}$ and creatinine $(\mathrm{R}=0.79)$ and eGFR $(\mathrm{R}=-0.72)$ on admission (P-value $<0.001)$ and the amount of the increase in cystatin $\mathrm{C}$ after 48 hours with creatinine $(\mathrm{R}=0.81)$ and eGFR $(\mathrm{R}=-$ $0.63)(\mathrm{P}<0.001)$.

In $9 \%$ of patients, creatinine rose by $0.3 \mathrm{mg} / \mathrm{dL}$ or more after two days. In the sample population, just eight patients of 200 met the R (Risk) category of the RIFLE classification by the creatinine criterion (a creatinine increases of $0.50 \%$ ), but 20 patients met the eGFR criterion" (a decrease in eGFR of $0.25 \%$ ). $(10 \%)$.However, only $14(43.8 \%)$ of the 32 patients with AKI, cystatin $\mathrm{C}$ had a relative elevation in creatinine greater than $0.3 \mathrm{mg} / \mathrm{dL}$. Creatinine levels were increased by more than $0.2 \mathrm{mg} / \mathrm{dL}$ in 20 of the 32 AKI cystatin $C$ patients (62.5\%), and eGFR decreased by more than $0.15 \mathrm{~mL} / \mathrm{min}$ in 15 patients $(46.9 \%)$.

Rates of AKI, cystatin C showed comparable results between men and women. Still, patients with elevated cystatin $\mathrm{C}$ levels on admission had a higher rate (25 percent vs. 11.9 percent, $\mathrm{P}=0.049$ ) than patients with normal renal function.

On admission,table (2) showed that there were no significant differences regarding serum creatinine and other routine laboratory tests (e.g., Sodium and CBC) between both groups. Cystatin C levels were elevated in 76 out of 200 patients on admission. Cystatin $\mathrm{C}$ on admission was significantly increased in group A $(1.5 \pm 0.53 \mathrm{mg} / \mathrm{L})$ compared to group B $(1.27$ $\pm 061 \mathrm{mg} / \mathrm{l})(\mathrm{P}$-value $=0.048)$.

Table (2): Laboratory results in the studied patients on admission:

\begin{tabular}{|l|c|c|c|c|}
\hline $\begin{array}{l}\text { Laboratory } \\
\text { parameter }\end{array}$ & $\begin{array}{c}\text { All, } \\
\boldsymbol{n = 2 0 0}\end{array}$ & $\begin{array}{c}\text { Group A } \\
\text { AKI, } \\
\boldsymbol{n = 3 2}\end{array}$ & $\begin{array}{c}\text { Group B } \\
\text { No AKI, } \\
\boldsymbol{n = 1 6 8}\end{array}$ & P-value \\
\hline $\begin{array}{l}\text { Hemoglobin, } \\
\text { g/L }\end{array}$ & 13.00 & $\begin{array}{c}12.2 \\
\pm 1.00\end{array}$ & $\begin{array}{c}13.1 \pm \\
2.00\end{array}$ & 0.092 \\
\hline Sodium, & 139 & $138 \pm$ & $139 \pm$ & \\
mmol/L & \pm 7.00 & 6.00 & 5.00 & 0.317 \\
\hline Creatinine, & $1.02 \pm$ & $1.02 \pm$ & $1.01 \pm$ & \\
mg/dL & 0.08 & 0.09 & 0.07 & 0.974 \\
\hline Cystatin C, & $1.30 \pm$ & $1.50 \pm$ & $1.27 \pm$ & \\
mg/L & 0.07 & 0.03 & 0.01 & 0.048 \\
\hline
\end{tabular}

Results are shown as means \pm SD

As shown in figure (2) to identify AKI, the cystatin $\mathrm{C}$ area under the curve was 0.91 . The rise of cystatin $\mathrm{C}$ level by $0.3 \mathrm{mg} / \mathrm{L}$ showed $91 \%$ specificity and $78 \%$ sensitivity.The percentage of patients diagnosed with acute kidney injury depends on the cutoff value and the renal function biomarker used, either cystatin $\mathrm{C}$ or creatinine.

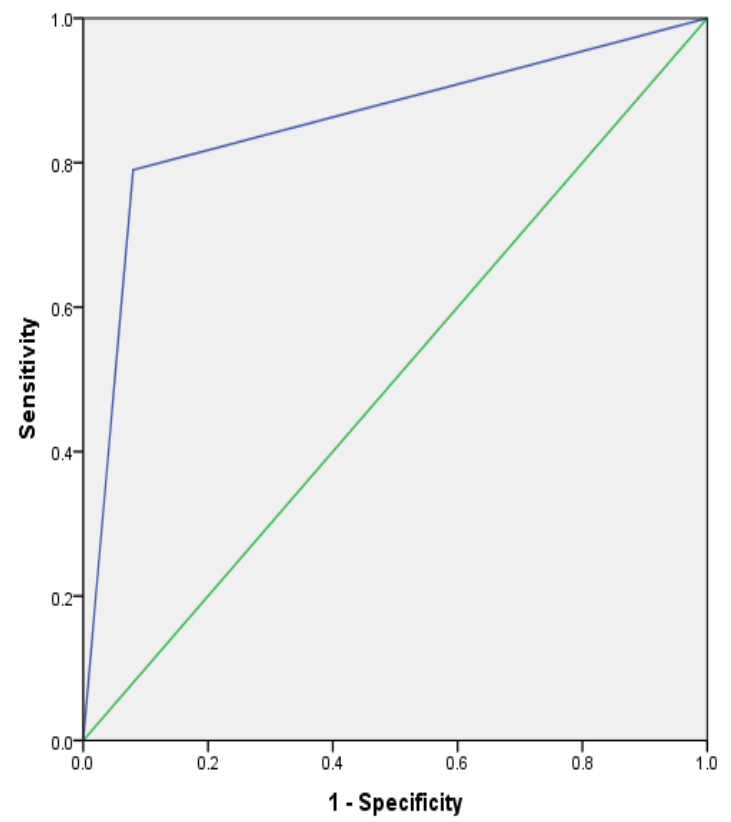

Fig. (2): Receiver-operating characteristic (ROC) curve

\section{DISCUSSION}

We evaluated cystatin $\mathrm{C}$ as an AKI biomarker of renal deterioration in patients diagnosed with AHF. Cystatin $\mathrm{C}$ can detect the decline in kidney function early during the first 48 hours after hospitalization. We reported that the increase by $\geq 0.3 \mathrm{mg} / \mathrm{L}$ in cystatin C led to longer hospital admission and was correlated with a non-significant increase in in-hospital mortality. Cystatin $\mathrm{C}$ can be used reliably as a diagnostic and prognostic biomarker for acute kidney injury in acute cardiorenal syndrome (CRS type1). Cystatin C levels, unlike creatinine, is unaffected by age, sex, muscle mass and diet. So, it represents the true GFR better than creatinine, which is affected by the previous factors. Cystatin $\mathrm{C}$ has been identified as an excellent serum biomarker of early acute renal injury ${ }^{(12,13,16)}$.

In a study conducted by Bellomo et al. ${ }^{(19)}$ in an intensive care unit, nearly $50 \%$ of the patients were diagnosed, using the RIFLE criteria, with acute renal injury. Cystatin $\mathrm{C}$ increase in those patients was more significant, increasing more than $50 \%$, and is detected 24 to 48 hours before creatinine. However, in the present study, only a few patients had a $50 \%$ or more rise in cystatin $\mathrm{C}$ or creatinine. it is recommended to have lower cut-offs with higher sensitivity to detect acute renal impairment efficiently ${ }^{(7,17,18)}$. During the last few years, the "RIFLE standards were used to classify acute renal failure, which was distinguished by the increase in creatinine by $50 \%$ (R criterion ) to 200 percent (L-criterion) (F-criterion)" ${ }^{19)}$.

According to several reports, increases in creatinine below $0.5 \mathrm{mg} / \mathrm{dL}$ have been linked to an 
elevated risk of death and rehospitalization in heart disease and other hospitalized patients $(7,8,20,21)$. The Acute Kidney Injury Network reported in 2007 that defined AKI amended the RIFLE standards to include more slight decreases in kidney function and indicated that deterioration that occurred within 48 hours should be expected for AKI to be defined ${ }^{(17)}$. The exact time for worsening renal function in AHF was highly variable ${ }^{(7,}$ 18).

In the present study, we reported the definition and the change in renal function threshold value that affects the incidence of acute renal failure in acute heart failure $^{(3,7)}$. Regarding our study, we assessed patients during the first 48 hours after admission, which is suggested by the definition of AKI. In our study, the increased cystatin $\mathrm{C}$ level $\geq 0.3 \mathrm{mg} / \mathrm{L}$ represented high specificity and reasonable sensitivity in identifying acute renal injury. This cut-off was separately correlated with adverse outcomes in the hospital.

Previous studies reported that the hospital stay might not be affected by changes in renal function if it was below a specific threshold value ${ }^{(7)}$. The present study confirmed a $\geq 0.3 \mathrm{mg} / \mathrm{L}$ rise in cystatin $\mathrm{C}$. Nevertheless, it is still adequately sensitive to distinguish patients having AKI in AHF settings.Good prognostic properties have been previously shown in a variety of cardiovascular disease populations. The cutoff value used to represent acute renal injury would often alter the marker's diagnostic and prognostic significance. We have to search for new biomarkers to detect secondary outcomes and not depend only on screening biomarkers ${ }^{(11,22,23)}$.

Although slight changes in creatinine have a high sensitivity but low specificity, significant changes have reasonable specificity but lower sensitivity for detecting AKI. ${ }^{(19)}$ Any conclusive findings on mortality risk prediction are limited due to the difference between groups of patients with AKI cystatinC and increased creatinine $>0.2 \mathrm{mg} / \mathrm{dL}^{(18,24)}$. It is reported that cystatin C has more substantial relationships with GFR and has the slightest affection by non-renal causes suggesting that cystatin $\mathrm{C}$ results are linked to prominent variations in renal function.

We explain part of the discrepancy by the high percentage of newly diagnosed AHF and the addition of patients already with acute cardiorenal syndrome(ACRS). Moreover, the patients were of average age, and half of them were females. We need to study and confirm the results of new AKI biomarkers in terms of the population, the proposed duration of 48 hours, and the percent of renal dysfunction needed for AKI diagnosis.

\section{STUDY LIMITATIONS}

A relatively small number. Lack of postdischarge follow-up. No available direct measurements of GFR to test changes in renal functions like in most studies.

\section{CONCLUSIONS}

Based on the results obtained in the present study, we could conclude that cystatin $\mathrm{C}$ can be considered a dependable biomarker for early deterioration of renal function in patients with acute (Type 1) cardiorenal syndrome (CRS) in AHF.

Cystatin $\mathrm{C}$, as a prognostic biomarker in acute CRS, also exhibits comparable results to creatinine and eGFR. An early deterioration in kidney function leads to an extended hospital stay and a slightly higher but insignificant in-hospital mortality rate. The current study suggests that we use cystatin $\mathrm{C}$ regularly to assess kidney damage, especially in AHF patients.

\section{REFERENCE}

1. Dickstein K, Cohen-Solal A, Filippatos G et al.(2008): The Task Force for the diagnosis and treatment of acute and chronic heart failure 2008 of the European Society of Cardiology. Developed in collaboration with the Heart Failure Association of the ESC (HFA) and endorsed by the European Society of Intensive Care Medicine (ESICM). Eur J Heart Fail., 10(10):933-89.

2. Nieminen M, Böhm M, Cowie M G et al.(2005): Executive summary of the guidelines on the diagnosis and treatment of acute heart failure the Task Force on Acute Heart Failure of the European Society of Cardiology. Eur Heart J., 26(4):384-416.

3. Smith G, Lichtman J, Bracken $M$ et al.(2006):Renal impairment and outcomes in heart failure: systematic review and meta-analysis. J Am Coll Cardiol., 47(10):1987-96.

4. Naruse H, Ishii J, Kawai T et al.(2009): Cystatin C in acute heart failure without advanced renal impairment. Am J Med., 122(6):566-73.

5. Ronco C, Haapio M, House A, Anavekar N, Bellomo R (2008): Cardiorenal syndrome. J Am Coll Cardiol., 52(19):1527-39.

6. Ronco C, McCullough P, Anker S et al.(2010):Cardiorenal syndromes: report from the consensus conference of the acute dialysis quality initiative. Eur Heart J., 31(6):703-11.

7. Damman K, Navis G, Voors A et al.(2007):Worsening renal function and prognosis in heart failure: systematic review and meta-analysis. J Card Fail., 13(8):599-608.

8. Smith G, Vaccarino $\mathrm{V}$, Kosiborod $\mathrm{M}$ et al.(2003):Worsening renal function: what is a clinically meaningful change in creatinine during hospitalization with heart failure? J Card Fail., 9(1):13-25.

9. Siirilä-Waris $\mathrm{K}$, Lassus $\mathrm{J}$, Melin $\mathrm{J}$ et al. (2006): Characteristics, outcomes, and predictors of 1year mortality in patients hospitalized for acute heart failure. Eur Heart J., 27(24):3011-7.

10. Han $X$, Zhang $S$, Chen $Z$ et al.(2020):Cardiac biomarkers of heart failure in chronic kidney disease. Clin Chim Acta, 510:298-310.

11. Shlipak M, Sarnak M, Katz R et al.(2005):Cystatin C and the risk of death and cardiovascular events among elderly persons. N Engl J Med.. 352(20):2049-60.

12. Herget-Rosenthal S, Marggraf G, Hüsing J et al.(2004):Early detection of acute renal failure by serum cystatin C. Kidney Int., 66(3):1115-22.

13. Coca $S$, Yalavarthy $R$, Concato $J$, Parikh (2008):Biomarkers for the diagnosis and risk 
stratification of acute kidney injury: a systematic review. Kidney Int., 73(9):1008-16.

14. Dharnidharka V, Kwon C, Stevens G (2002): Serum cystatin $\mathrm{C}$ is superior to serum creatinine as a marker of kidney function: a meta-analysis. Am J Kidney Dis., 40(2):221-6.

15. Laterza O, Price C, Scott M(2002):Cystatin C: an improved estimator of glomerular filtration rate? Clin Chem., 48(5):699-707.

16. Chen S, Tang Y, Zhou X (2019): Cystatin C for predicting all-cause mortality and rehospitalization in patients with heart failure: a meta-analysis. Biosci Rep., 39(2): 1 .

17. Mehta R, Kellum J, Shah S et al.(2007): Acute Kidney Injury Network: report of an initiative to improve outcomes in acute kidney injury. Crit Care, 11(2):R31.

18. Coca S, Peixoto A, Garg A et al. (2007): The prognostic importance of a small acute decrement in kidney function in hospitalized patients: a systematic review and meta-analysis. Am J Kidney Dis., 50(5):712-20.

19. Bellomo R, Ronco C, Kellum J et al. (2004): Acute renal failure - definition, outcome measures, animal models, fluid therapy and information technology needs: the Second International Consensus Conference of the Acute Dialysis Quality Initiative (ADQI) Group. Crit Care, 8(4):204-12.

20. Forman D, Butler J, Wang Y et al.(2004):Incidence, predictors at admission, and impact of worsening renal function among patients hospitalized with heart failure. J Am Coll Cardiol., 43(1):61-7.

21. Lassus J, Nieminen M, Peuhkurinen $\mathrm{K}$ et al.(2010): Markers of renal function and acute kidney injury in acute heart failure: definitions and impact on outcomes of the cardiorenal syndrome. Eur Heart J., 31(22):27918 .

22. Lassus J, Harjola V, Sund R et al.(2007): Prognostic value of cystatin $\mathrm{C}$ in acute heart failure in relation to other markers of renal function and NT-proBNP. Eur Heart J., 28(15):1841-7.

23. Jernberg T, Lindahl B, James S et al. (2004): Cystatin C: a novel predictor of outcome in suspected or confirmed non-ST-elevation acute coronary syndrome. Circulation, 110(16):2342-8.

24. Waikar S, Betensky R, Bonventre J (2009): Creatinine as the gold standard for kidney injury biomarker studies? Nephrol Dial Transplant., 24(11):3263-5. 